\title{
The Importance of Service
}

Learning in Dermatology Residency: An Actionable Approach to Improve Resident Education and
Skin Health Equity

Victoria S. Humphrey, BS; Alaina J. James, MD, PhD

\section{PRACTICE POINTS}

- In 2019, nearly 30 million Americans did not have health insurance. Dermatologists in the United States should be cognizant of the challenges faced by underserved patients when accessing dermatologic care.

- Service learning is an educational approach that combines learning objectives with community service to provide a comprehensive learning experience, meet societal needs, and fulfill Accreditation Council for Graduate Medical Education requirements.

- Actionable methods to increase service learning in dermatology residency training include volunteering in community service programs offered by national dermatology organizations, implementing servicelearning projects, and partnering with free and federally funded community practices.

- Dermatology residents who participate in service learning will help increase access to equitable dermatologic care and experience practicing in settings with limited resources.
Accessing specialty care such as dermatology is a challenge for patients residing in marginalized communities. In 2019, there were nearly 30 million individuals without health insurance in the United States; furthermore, those from minority backgrounds are less likely to be insured than their White counterparts. Service learning is an educational approach that combines learning objectives with community service to provide a comprehensive scholastic experience, meet societal needs, and fulfill Accreditation Council for Graduate Medical Education requirements. A commitment to service learning in dermatology residency programs will improve skin health equity as well as dermatology residency education relating to cultural competency and socioeconomic determinants of health.

Cutis. 2021;107:120-122.

$\Lambda$ ccess to specialty care such as dermatology is a challenge for patients living in underserved communities. ${ }^{1}$ In 2019, there were 29.6 million individuals without health insurance in the United States$9.2 \%$ of the population - up from 28.6 million the prior year. ${ }^{2}$ Furthermore, Black and Hispanic patients, American Indian and Alaskan Natives, and Native Hawaiian and other Pacific Islanders are more likely to be uninsured than their White counterparts. ${ }^{3}$ Community service activities such as free skin cancer screenings, partnerships with community practices, and teledermatology consultations through free clinics are instrumental in mitigating health care disparities and improving access to dermatologic care. In this article, we build on existing models from dermatology residency programs across the country to propose actionable methods to expand service-learning opportunities in dermatology residency training and increase health care equity in dermatology.

\section{Why Service Learning?}

Service learning is an educational approach that combines learning objectives with community service to provide a comprehensive scholastic experience and meet societal needs. ${ }^{4}$ In pilot studies of family medicine residents, service-learning initiatives enhanced the standard residency curriculum by promoting clinical practice resourcefulness. ${ }^{5}$ Dermatology Accreditation Council for Graduate

Ms. Humphrey is from the University of Pittsburgh School of Medicine, Pennsylvania. Dr. James is from the Department of Dermatology, University of Pittsburgh Medical Center.

The authors report no conflict of interest.

Correspondence: Victoria S. Humphrey, BS, 3708 Fifth Ave, Ste 500.68, Pittsburgh, PA 15213 (vsh6@pitt.edu).

doi:10.12788/cutis.0199 
Medical Education requirements mandate that residents demonstrate an awareness of the larger context of health care, including social determinants of health. ${ }^{6}$ Likewise, dermatology residents must recognize the impact of socioeconomic status on health care utilization, treatment options, and patient adherence. With this understanding, residents can advocate for quality patient care and improve community-based health care systems. ${ }^{6}$

Service-learning projects can effectively meet the specific health needs of a community. In a service-learning environment, residents will understand a communitybased health care approach and work with attending physician role models who exhibit a community service ethic. ${ }^{7}$ Residents also can gain interprofessional experience through collaborating with a team of social workers, community health workers, care coordinators, pharmacists, nurses, medical students, and attending physicians. Furthermore, residents can practice communicating effectively with patients and families across a range of socioeconomic and cultural backgrounds. Interprofessional, team-based care and interpersonal skill acquisition are both Accreditation Council for Graduate Medical Education requirements for dermatology training. ${ }^{6}$ Through increased service-learning opportunities, dermatology trainees will learn to recognize and mitigate social determinants of health with a holistic, patientcentered treatment plan.

Free or low-cost medical clinics provide health care to more than 15 million Americans, many of whom identify with marginalized racial and ethnic groups. ${ }^{8}$ In a dermatology access study, a sample of clinics listed in the National Association of Free and Charitable Clinics database were contacted regarding the availability of dermatologic care; however, more than half of the sites were unresponsive or closed, and the remaining clinics offered limited access to dermatology services. ${ }^{9}$ The scarcity of free and low-cost dermatologic services likely contributes to adverse skin health outcomes for patients in underserved communities. ${ }^{10}$ By increasing service learning within dermatology residency training programs, access to dermatologic care will improve for underserved and uninsured populations.

\section{Actionable Methods to Increase Service Learning in Dermatology Residency Training Programs}

Utilize Programming Offered Through National Dermatology Associations and Societies-The American Academy of Dermatology (AAD) has developed programming through which faculty, residents, and private practice dermatologists perform community service targeting underserved populations. SPOT me (https://www.aad.org/member/career /volunteer/spot), a skin cancer screening program, is the AAD's longest-standing public health program through which it provides complimentary screening forms, handouts, and advertisements to facilitate skin cancer screening. AccessDerm (https://www.aad.org/member/career /volunteer/access-derm) is the AAD's philanthropic teleder- matology program that delivers dermatologic care to underserved communities. Camp Discovery (https://www.aad.org /member/career/volunteer/camp) and the Shade Structure Grant Program (https://www.aad.org/public/public-health /shade-structure-grants) are additional initiatives promoted by the AAD to support volunteer services for communities while learning about dermatology. Residents may apply for AAD grants to subsidize participation in the Native American Health Service Resident Rotation Program (https://www.aad.org/member/career/awards/native -american), the Skin Care for Developing Countries program (https://www.aad.org/member/career/awards /developing-countries), or an international grant (https: //www.aad.org/member/career/awards/resident-international).

The Women's Dermatologic Society hosts 3 primary umbrella community outreach initiatives (https://www .womensderm.org/community/service-and-outreach -programs): Play Safe in the Sun, Coast-2-Coast, and the Transforming Interconnecting Project Program Women's Shelter Initiative. From uplifting and educating individuals in women's shelters about skin care, oral hygiene, self-care, nutrition, and social skills to providing complimentary skin cancer screenings, the Women's Dermatologic Society provides easily accessible tool kits and syllabi to facilitate project composition and completion by its members.

Implement Residency Class Service-Learning ProjectsIncoming dermatology residents are regularly encouraged to draft research proposals at the beginning of each academic year. Encouraging residency classes to work collectively on

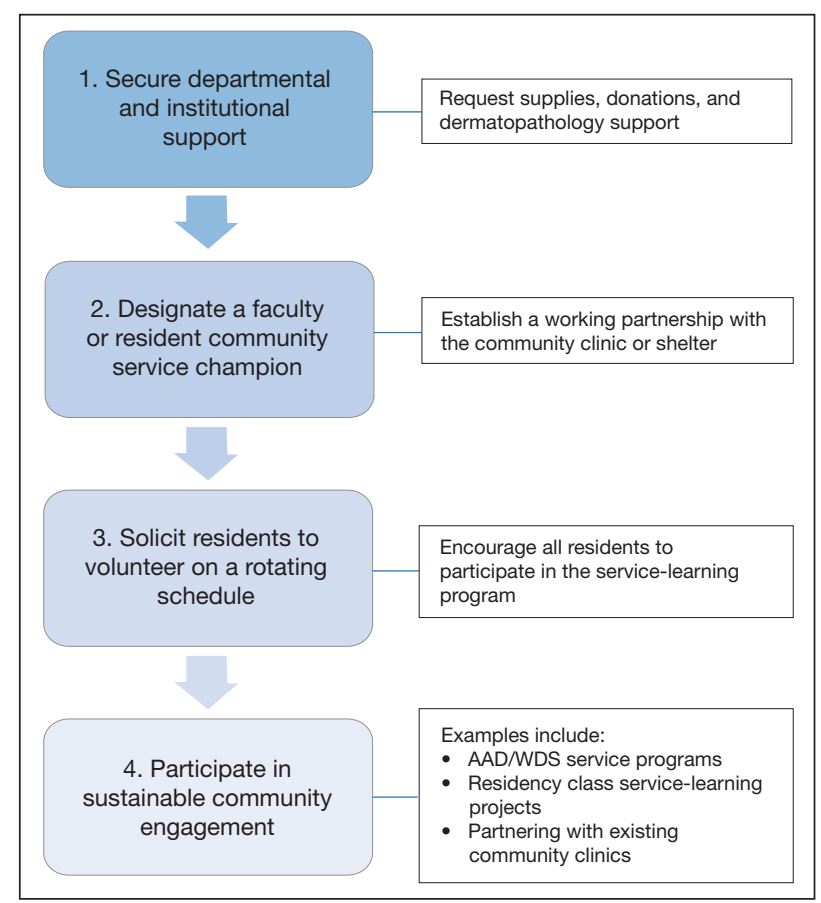

Action items to build community partnerships for dermatology service learning. AAD indicates American Academy of Dermatology; WDS, Women's Dermatologic Society. 
a dermatology service-learning project likely will increase resident camaraderie and project success while minimizing internal competition. In developing a service-learning proposal, residents should engage with community leaders and groups to best understand how to meet the skin health needs of underserved communities. The project should have clear objectives, benchmarks, and full support of the dermatology department. Short-term service-learning projects are completed when set goals are achieved, while sustainable projects continue with each new resident class.

Partner With Existing Community or Federally Funded Clinics-Establishing partnerships with free or federally funded health centers is a reliable way to increase service-learning opportunities in dermatology residency training. Personal malpractice carriers often include free clinic coverage, and most states offer limited liability or immunity for physicians who volunteer their professional services or subsidize malpractice insurance purchases. ${ }^{11}$ In light of the global coronavirus disease 2019 pandemic, teledermatology options should be explored alongside in-person services. Although logistics may vary based on institutional preference, the following are our recommendations for building community partnerships for dermatology service learning (Figure):

- Secure departmental and institutional support. This includes requesting supplies, donations, and dermatopathology support

- Designate a resident or faculty community service champion to lead clinic correspondence and oversee operative logistics. This individual will establish a working partnership with the community clinic, assess the needs of the patient population, and manage the clinic schedule. The champion also will initiate and maintain open lines of communication with community providers for continuity of care. This partnership with community providers allows for shared resources and mutual learning

- Solicit residents to volunteer on a rotating schedule. Although some residents are fully committed to community service and health care justice, all residents need to participate in the service-learning program

- Participate in sustainable community engagement on a schedule that suits the needs of the community and takes into consideration resident and attending availability

\section{Final Thoughts}

Service learning in dermatology residency training is essential to improve access to equitable dermatologic care and train clinically competent dermatologists who have experience practicing in resource-limited settings. Service learning places cultural awareness and an understanding of socioeconomic determinants of health at the forefront. ${ }^{12}$ Some dermatology residency programs treat a high percentage of medically underserved patients; others have integrated service learning into dermatology rotations, and a few programs offer community engagement-focused residency tracks. ${ }^{13-16}$ Each dermatology program should evaluate its workforce, resources, and nearby underserved communities to strategically develop a program-specific service-learning program. Service-learning clinics often are the sole means by which patients from underserved communities receive dermatologic care. ${ }^{17}$ A commitment to service learning in dermatology residency programs will improve skin health equity and improve dermatology residency education.

\section{REFERENCES}

1. Cook NL, Hicks LS, O'Malley J, et al. Access to specialty care and medical services in community health centers. Health Aff (Millwood). 2007;26:1459-1468.

2. Broaddus M, Aron-Dine A. Uninsured rate rose again in 2019, further eroding earlier progress. Center on Budget and Policy Priorities website. Published September 15, 2020. Accessed February 9, 2021. https://www .cbpp.org/research/health/uninsured-rate-rose-again-in-2019-further -eroding-earlier-progress

3. Artiga S, Orgera K, Damico A. Changes in health coverage by race and ethnicity since the ACA, 2010-2018. Kaiser Family Foundation website. Published March 5, 2020. Accessed February 9, 2021. https://www.kff .org/racial-equity-and-health-policy/issue-brief/changes-in-health -coverage-by-race-and-ethnicity-since-the-aca-2010-2018/

4. Martinez MG. H.R.2010 - 103rd Congress (1993-1994): National and Community Service Trust Act of 1993. AmeriCorps website. Accessed November 24, 2020. https://www.congress.gov/bill/103rd-congress /house-bill/2010

5. Gefter L, Merrell SB, Rosas LG, et al. Service-based learning for residents: a success for communities and medical education. Fam Med. 2015;47:803-806

6. ACGME Program Requirements for Graduate Medical Education in Dermatology. Accreditation Council for Graduate Medical Education website. Updated July 1, 2020. Accessed February 9, 2021. https://acgme .org/Portals/0/PFAssets/ProgramRequirements/080_Dermatology _2020.pdf?ver=2020-06-29-161626-133

7. Blanco G, Vasquez R, Nezafati $K$, et al. How residency programs can foster practice for the underserved. J Am Acad Dermatol. 2012;67:158-159.

8. Darnell JS. Free clinics in the United States: a nationwide survey. Arch Intern Med. 2010;170:946.

9. Madray V, Ginjupalli S, Hashmi O, et al. Access to dermatology services at free medical clinics: a nationwide cross-sectional survey. J Am Acad Dermatol. 2019;81:245-246.

10. Shi L, Stevens GD.Vulnerability and unmet health care needs: the influence of multiple risk factors. J Gen Intern Med. 2005;20:148-154.

11. Benrud L, Darrah J, Johnson A. Liability considerations for physician volunteers in the US. Virtual Mentor. 2010;12:207-212.

12. Service-learning plays vital role in understanding social determinants of health. AAMC website. Published September 27, 2016. Accessed February 22, 2021. https://www.aamc.org/news-insights/service -learning-plays-vital-role-understanding-social-determinants-health

13. Sheu J, Gonzalez E, Gaeta JM, et al. Boston Health Care for the Homeless Program-Harvard Dermatology collaboration: a service -learning model providing care for an underserved population. J Grad Med Educ. 2014;6:789-790.

14. OjedaVD, Romero L, Ortiz A. A model for sustainable laser tattoo removal services for adult probationers. Int J Prison Health. 2019;15:308-315.

15. Diversity \& Community Track (Dermatology Diversity and Community Engagement residency position). Penn Medicine Dermatology website. Accessed February 9, 2021. https://dermatology.upenn.edu/residents /diversity-community-track/

16. Duke Dermatology Diversity and Community Engagement residency position (1529080A2). Duke Dermatology website. Accessed February 9, 2021. https://dermatology.duke.edu/node/4742

17. Buster KJ, Stevens EI, Elmets CA. Dermatologic health disparities. Dermatol Clin. 2012;30:53-59. 